\title{
$\mathrm{Ti}$ 합금과 철강의 이종재료 접합공정 특성 리뷰
}

\author{
유현정* - 이태현* · 강민정* · 김철희 ${ }^{* * *,+}$ \\ *한국생산기술연구원 접합적층연구부문 \\ **포틀랜드주립대학 기계재료공학과
}

\section{Process Review on Dissimilar Metal Joining of Steel and Ti Alloys}

Hyeonjeong You*, Taehyun Lee*, Minjung Kang*, and Cheolhee Kim*,**, $\dagger$

*Advanced Joining \& Additive Manufacturing R\&D Department, KITECH, Incheon, 21999, Korea

**Department of Mechanical and Materials Engineering, Portland State University, OR 97229, USA

†Corresponding author: chkim@kitech.re.kr

(Received August 2, 2021; Revised September 24, 2021; Accepted November 1, 2021)

\begin{abstract}
Titanium alloys have high specific strength and excellent high-temperature properties. However, Ti alloys have limited weldability with other metals due to the formation of brittle intermetallic compounds. Moreover, when steel is a counterpart of dissimilar metal joining, the soundness of weld is hardly achieved due to weld defects. Numerous studies have been conducted to achieve joint strength by minimizing the effects of Fe-Ti intermetallic compounds. In most studies, pure titanium or Ti-6Al-4V alloy were selected as the Ti base metal, whereas stainless steel, low carbon steel, or alloy steel were selected as the steel base metal. To date, joining processes such as diffusion bonding, brazing, fusion welding, and solid-state joining have been investigated. In this study, the characteristics of each of these joining processes were reviewed. More specifically, the formation of intermetallic compounds was analyzed when Ti alloy and steel were directly joined without using interlayer materials.
\end{abstract}

Key Words: Titanium alloy, Steel, Dissimilar metal welding, Diffusion welding, Brazing, Solid state welding, Fusion welding, Intermetallic compound

\section{1. 서 론}

$\mathrm{Ti}$ 합금은 비강도와 내식성이 우수하여 항공부품, 발 전/화학 플랜트 등 주요 구조부품 뿐 아니라 형상기억 합금, 패션 용품 등에 사용되고 있다 ${ }^{1)}$. Ti 합금은 고 온에서 산소와의 반응성이 높아 진공 중에서 공정이 이 루어지는 전자빔 용접이나 충분한 보호가스 분위기 하 에서 레이저 용접이나 아크 용접공정을 이용하여 용접 하고 있으며2), 대표적으로 $a$ 형 합금인 순수 $\mathrm{Ti}$ 금속과 $\alpha+\beta$ 형 합금인 Ti- $6 \mathrm{Al}-4 \mathrm{~V}$ 합금이 용접구조에 주로 이 용되고 있다

$\mathrm{Ti}$ 합금의 사용이 증가함에 따라 $\mathrm{Ti}$ 합금과 철계 소 재의 이종재료 접합에 대한 관심이 높아지고 있다. 그
러나 Fig. 1의 상태도에서 확인할 수 있듯이 $\mathrm{FeTi}$, $\mathrm{Fe}_{2} \mathrm{Ti}$ 등 취성이 강한 금속간 화합물(Intermetallic

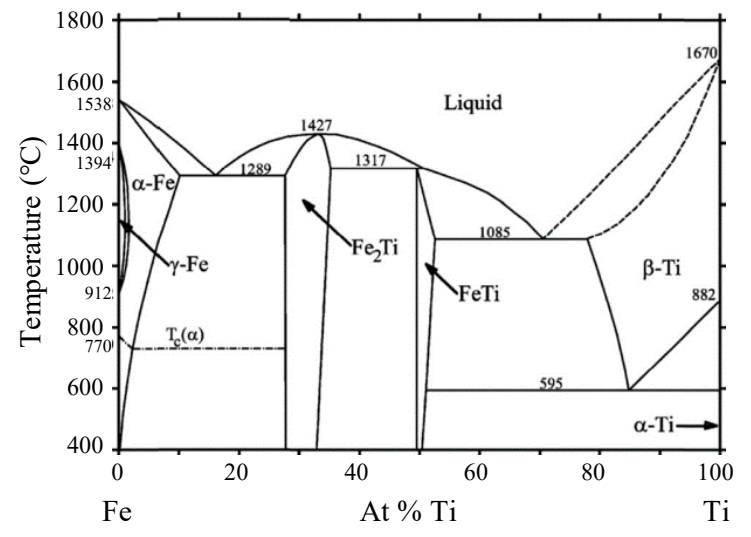

Fig. 1 Ti-Fe binary Phase diagram ${ }^{3,4)}$ 
Table 1 The thermal and mechanical properties of STS 304 and Ti-6Al-4V alloy)

\begin{tabular}{|c|c|c|}
\hline & STS 304 & Ti-6Al-4V* \\
\hline Melting temperature $\left({ }^{\circ} \mathrm{C}\right)$ & $1400-1455$ & $1636-1660$ \\
\hline $\begin{array}{c}\text { Thermal expansion } \\
\text { coefficient } \\
\left(10^{-6} / \mathrm{K}\right)\end{array}$ & $17.3-18.7$ & $9-9.7$ \\
\hline $\begin{array}{c}\text { Thermal conductivity } \\
(\mathrm{W} / \mathrm{m} \cdot \mathrm{K})\end{array}$ & $16.2-21.5$ & $6.6-17.5$ \\
\hline $\begin{array}{c}\text { Density }\left(\mathrm{g} / \mathrm{cm}^{3}\right) \\
\text { Tensile strength }(\mathrm{MPa})\end{array}$ & 8.00 & 4.42 \\
\hline Elongation $(\%)$ & 70 & 985 \\
\hline
\end{tabular}

compound, IMC)이 형성되는 문제점이 있다3,4). 또 한 Table 1 의 물리적.기계적 특성을 확인해 보았을 때 두 모재간의 열적 특성이 크게 차이나기 때문에 전통적 용융용접을 할 경우 양측 모재에 열 변형과 용접 후 계 면에서 잔류 응력이 발생하게 된다 ${ }^{5,6)}$. 이로 인해 접합 부에서 균열이 발생하기 때문에, $\mathrm{Ti}$ 합금과 철계 소재 의 이종재료 접합에는 브레이징, 확산접합이나 마찰용 접, 폭발용접과 같은 고상용접이나 고에너지/저입열 용 접 등이 적용되고 있다 ${ }^{7)}$.

본 논문에서는 기존 연구결과를 확산접합, 브레이징, 용융용접 외 고상접합으로 나누어 기존 발표되는 공정 의 특성을 리뷰하고 특히 중간층 없이 $\mathrm{Ti}$ 합금과 $\mathrm{Fe}$ 계 소재가 용접될 경우의 IMC 거동에 대해 고찰하고자 한다.

\section{2. 확산접합}

확산접합은 Fig. 2와 같이 접합면을 가압하면서 가 열하여 접합면 사이에서 서로간의 원자 확산이 발생하 고, 이를 통해 접촉된 표면이 접합되는 방법으로, (a) 접촉상태, (b) 고온크립, (c) 입계 및 보이드 소멸, (d) 체확산 보드 소실 과정으로 진행된다 ${ }^{8)}$. 확산접합은 크 게 중간 삽입재를 사용한 경우와 사용하지 않는 경우로 나눌 수 있는데 각 경우에 대해서 소개하고자 한다 (Table 2).

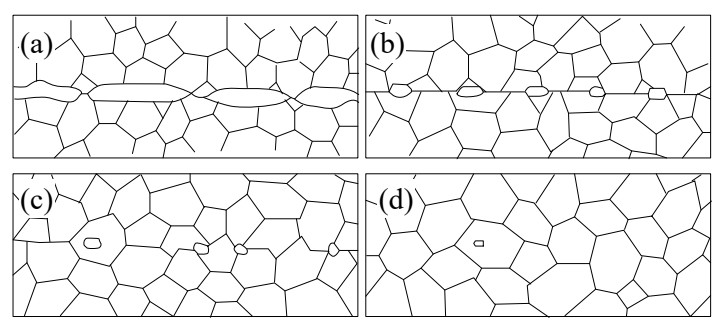

Fig. 2 Schematic of diffusion bonding process ${ }^{8)}$
Ghosh et al. ${ }^{9-11)}$ 은 중간 삽입재 없이 순 Ti 금속과 STS 304 소재의 확산접합 온도 $\left(800-950{ }^{\circ} \mathrm{C}\right)$ 와 시간 (1-2 hr)에 따른 접합부의 강도와 계면에 형성되는 $\mathrm{IMC}$ 거동을 관찰하였다. 접합 시간과 관계없이 850 ${ }^{\circ} \mathrm{C}$ 에서 가장 높은 인장 강도를 가졌으며, 온도가 증가 함에 따라 강도가 감소하는 경향을 나타내었다. 접합부 에서 $\sigma$ 상, $\mathrm{FeTi}, \mathrm{Fe}_{2} \mathrm{Ti}_{1}, \mathrm{Fe}_{2} \mathrm{Ti}_{4} \mathrm{O}$ 등의 $\mathrm{IMC}$ 가 관찰 되었다.

Kundu et al.은 순 $\mathrm{Ti}$ 금속과 석출경화형 17-4 PH STS 소재 ${ }^{12)}$ (850-950 ${ }^{\circ} \mathrm{C}, 2 \mathrm{hr}$ ) 또는 오스테나 이트-페라이트 구조로 이루어진 듀플렉스 STS 소재 ${ }^{13)}$ (800-950 ${ }^{\circ} \mathrm{C}, 1.5 \mathrm{hr}$ ) 를 각각 중간 삽입재 없이 확 산접합하였다. 17-4 PH STS 소재와의 이종접합부에 서는 $\sigma$ 상, $\mathrm{Fe}_{2} \mathrm{Ti}, \mathrm{FeTi}, \mathrm{Cr}_{2} \mathrm{Ti}, \mathrm{x}, \mathrm{a}-\mathrm{Fe}, \mathrm{a}-\mathrm{Ti}$ 와 $\beta-$ $\mathrm{Ti}$ 가 관찰되었으며, 듀플렉스 STS 소재와의 이종접합 부에서는 $a-\mathrm{Fe}+\lambda, \lambda+\mathrm{FeTi}, \mathrm{FeTi}+\beta-\mathrm{Ti}$ 와 $\beta-\mathrm{Ti}$ 상 이 관찰되었다.

Kaya et al. ${ }^{14)}$ 은 Ti-6Al-4V 합금과 IF 강재를 중 간 삽입재 없이 $900{ }^{\circ} \mathrm{C}$ 와 $950{ }^{\circ} \mathrm{C}$ 에서 30 분 동안 확 산접합하였다. 확산접합 온도가 증가함에 따라 $\mathrm{IMC}$ 결정립 성장으로 인해 부피 분율이 증가하고, 취성이 커지기 때문에 강도가 감소하는 경향을 나타내었다.

중간 삽입재를 사용하지 않은 경우 고온에서 $\mathrm{Ti}$ 이 화 학적으로 잘 반응하기 때문에 $\mathrm{Ti}$ 과 스테인리스강 계면 의 반응 구역에서 $\sigma, x, \lambda \mathrm{FeTi}, \mathrm{Fe}_{2} \mathrm{Ti}, \beta-\mathrm{Ti}$ 및 $\mathrm{Fe}_{2} \mathrm{Ti}_{4} \mathrm{O}$ 상 등 취성의 금속간 화합물이 형성되며, 접합 부의 기계적 특성을 저하시켰다. 따라서 접합 품질을 향상시키기 위해 중간 삽입재로 $\mathrm{Cu}, \mathrm{Ag}, \mathrm{Ni}$ 등 여러 합금을 사용한 결과가 보고되고 있다.

Kundu et al.은 순 Ti 금속과 STS 304 소재에 중간 삽입재로 $300 \mathrm{um}$ 두께를 가지는 $\mathrm{Cu}^{15)}\left(850-950{ }^{\circ} \mathrm{C}\right.$, $1.5 \mathrm{hr}$ ) 및 $\mathrm{Ni}^{16)}\left(800-950{ }^{\circ} \mathrm{C}, 3 \mathrm{hr}\right)$ 을 사용하였다. $\mathrm{Cu}$ 를 중간 삽입재로 사용한 경우 최적조건인 $900{ }^{\circ} \mathrm{C}$ 에서 $318 \mathrm{MPa}$ 의 최대 인장강도를 나타냈다. 상대적 으로 낮은 $850{ }^{\circ} \mathrm{C}$ 에서는 낮은 접합온도로 인해 불완전 한 유착이 발생하였고, $950{ }^{\circ} \mathrm{C}$ 에서는 온도가 증가함에 따라 취성 금속간 화합물의 부피분율이 증가하여 강도 가 감소했다. 중간 삽입재로 $\mathrm{Ni}$ 를 사용한 경우 $850{ }^{\circ} \mathrm{C}$ 에서 $\mathrm{Ti}$ 이 STS 쪽으로 확산되는 것을 $\mathrm{Ni}$ 중간층이 완 전히 차단하여 $270 \mathrm{MPa}$ 의 최대 인장강도를 나타내었 으며, $900{ }^{\circ} \mathrm{C}$ 이상에서는 확산을 차단하지 못하기 때 문에 강도가 감소했다. 또 다른 소재 조합으로는 $\mathrm{Ti}^{-}$ $6 \mathrm{Al}-4 \mathrm{~V}$ 합금과 17-4 PH STS 소재에 대해 $150 \mu \mathrm{m}$ 두께의 $\mathrm{Ni}$ 합금을 사용하여 확산접합한 연구결과가 있 
Table 2 Summary of diffusion bonding research for Ti/Steel dissimilar metal joining

\begin{tabular}{|c|c|c|c|c|c|}
\hline $\mathrm{Ti}$ & Steel & Interlayer & $\begin{array}{c}\text { Process temp. } \\
\left({ }^{\circ} \mathrm{C}\right)\end{array}$ & $\begin{array}{c}\text { Process time } \\
(\mathrm{h})\end{array}$ & $\begin{array}{c}\text { Author, } \\
\text { publication year }\end{array}$ \\
\hline Pure Ti & STS 304 & & $850-900$ & 1 & Ghosh, 2002 $^{9)}$ \\
\hline Pure Ti & STS 304 & & $850-950$ & 2 & Ghosh, 2003 $^{10)}$ \\
\hline Pure Ti & STS 304 & $800-950$ & 1.5 & Ghosh, 2003 ${ }^{11)}$ \\
\hline Pure Ti & 17-4 PH STS & & $850-950$ & 2 & Kundu 2006 ${ }^{12)}$ \\
\hline Pure Ti & micro-duplex STS & & $800-950$ & 1.5 & Kundu, 2008 ${ }^{13)}$ \\
\hline Ti-6Al-4V & IF steel & & 900,950 & 0.5 & Kaya, 2017 \\
\hline Pure Ti & STS 304 & Cu & $850-950$ & 1.5 & Kundu, 2005 ${ }^{15)}$ \\
\hline Pure Ti & STS 304 & Ni & $800-950$ & 3 & Kundu, 2008 \\
\hline Ti-6Al-4V & 17-4PH & Ni alloy & $800-900$ & 0.75 & Kundu, 2013 \\
\hline Ti-6Al-4V & STS 321 & AlMg6 & $350-600$ & Not given & He, 2008 \\
\hline Pure Ti & Low carbon steel & Cu-12Mn-2Ni & 800,850 & $0.5-3$ & Elrafaey, 2009 \\
\hline
\end{tabular}

다 ${ }^{17)}$. 접합 조건은 $800 \sim 900{ }^{\circ} \mathrm{C}$ 까지 $25{ }^{\circ} \mathrm{C}$ 간격의 온도에 대해서 45 분, $900{ }^{\circ} \mathrm{C}$ 에서 $5,15,30,45$ 분에 대해 총 8가지 조건으로 진행했다. 온도와 시간에 따른 경향을 확인해본 결과 온도가 증가할수록 IMC 길이가 증가하고, 시간이 증가함에 따라 중간층인 $\mathrm{Ni}$ 합금이 $\mathrm{Ti}$ 확산을 차단하지 못하는 것이 확인되었다.

$\mathrm{He}$ et $\mathrm{al}^{18)}$ 은 $\mathrm{Ti}-6 \mathrm{Al}-4 \mathrm{~V}$ 합금과 STS 321 소재 에 대해 중간 삽입재로 $500 \mathrm{um}$ 두께의 $\mathrm{Al}$ 합금을 사 용했다. 350-500 ${ }^{\circ} \mathrm{C}$ 온도 범위에 대해 접합 경향을 확인했으며, $450{ }^{\circ} \mathrm{C}$ 에서 $\mathrm{IMC}$ 가 거의 형성되지 않은 접합부를 형성하며 최대 인장강도를 나타내었다. 확산 시간이 증가하면 STS/Al 계면에 IMC 형성으로 인해 강도가 저하되었다.

Elrafaey et al. ${ }^{19)}$ 은 순 Ti 금속과 저탄소강에 대해 중간 삽입재로 $\mathrm{Cu}-12 \mathrm{Mn}-2 \mathrm{Ni}$ 을 사용하였다. $\mathrm{Ti}-\mathrm{Fe}$ $\mathrm{IMC}$ 나 $\mathrm{Ti}-\mathrm{C} \mathrm{IMC}$ 는 형성되지 않았으며, 보다 취성이 낮은 $\mathrm{Ti}_{2} \mathrm{Cu}$ 나 $\mathrm{TiCu}$ 와 같은 $\mathrm{Cu}-\mathrm{Ti} \mathrm{IMC}$ 가 형성되어 안정된 강도 확보가 가능하였다고 보고하였다.

\section{3. 브레이징}

브레이징은 Fig. 3과 같이 접합하고자 하는 두 모재 사이에 $450{ }^{\circ} \mathrm{C}$ 이상의 융점을 가지는 용가재를 삽입하 고 모재의 고상선 온도 이하의 열을 가하면서 용가재만 용융시켜, 두 모재 사이에 젖음 현상과 모세관 현상에 의해 침투 및 확산을 통해 접합하는 방법이다 ${ }^{8)}$. 브레 이징을 적용한 $\mathrm{Ti}$ 합금과 철계 소재의 이종재료 접합 연구는 Table 3 에 요약하였다.

Camargo et $\mathrm{al}^{20)}$ 은 순 Ti 금속과 STS 304 소재
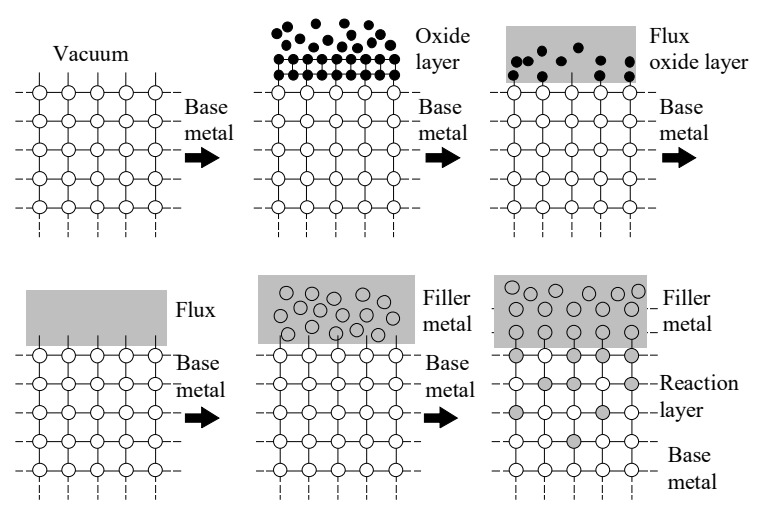

Fig. 3 Schematic of brazing process ${ }^{8)}$

에 $20 \mu \mathrm{m}$ 두께의 $\mathrm{Ag}-\mathrm{Cu}$ 삽입재를 넣어 접합했다. 삽 입재의 $\mathrm{Cu}$ 함량에 따라 접합부 특성을 확인해본 결과 함량이 증가하면 삽입재 내 $\mathrm{Ti}$ 함량이 증가하여 $\mathrm{Ti}$ 와 $\mathrm{Fe}$ 사이의 금속간 화합물 형성 속도가 빨라지므로 강 도가 저하된다.

Liu et al. ${ }^{21}$ 은 세 가지 종류의 은납을 이용하여 $\mathrm{Ti}^{-}$ $6 \mathrm{Al}-4 \mathrm{~V}$ 합금과 STS 304 소재의 진공브레이징을 840-900 ${ }^{\circ} \mathrm{C}$ 에서 수행하였다. 접합부에 $\mathrm{TiCu}, \mathrm{Ti}_{2} \mathrm{Cu}$, $\mathrm{Ti}_{2} \mathrm{Cu}_{3}, \mathrm{Cu}-\mathrm{Sn}-\mathrm{Ti} \mathrm{IMC}$ 형성이 확인되었으며, 적용 한 은납 필러에 따라 적정온도에서는 양호한 계면 형성 이 가능하였다.

Atasoy et al. ${ }^{22)}$ 은 순 $\mathrm{Ti}$ 금속과 저탄소강의 소재 에 중간 삽입재로 $80 \mu \mathrm{m}$ 두께의 $\mathrm{Ag}$ 합금을 사용하였 다. 브레이징 온도와 시간을 각각 $700-850{ }^{\circ} \mathrm{C}, 30-$ 120 분으로 설정하여 총 16 개 조건으로 실험한 결과 $850{ }^{\circ} \mathrm{C}, 90$ 분에서 $450 \mathrm{Hv}$ 로 가장 높은 경도를 나타 내었다. 접합 온도와 시간이 증가함에 따라 중간재 면 
Table 3 Summary of brazing research for Ti/Steel dissimilar metal joining

\begin{tabular}{|c|c|c|c|c|}
\hline Ti & Steel & Interlayer & Process & $\begin{array}{c}\text { Author, } \\
\text { publication year }\end{array}$ \\
\hline Pure Ti & STS 304 & 28Ag-Cu, 46Ag-Cu & Vacuum brazing & Camargo, 1993 ${ }^{20)}$ \\
\hline Ti-6Al-4V & STS 304 & silver based fillers & Vacuum brazing & Liu, 2002 \\
\hline Pure Ti & Low carbon steel & AgCuZn & Vacuum brazing & Atasoy, 2008 ${ }^{22)}$ \\
\hline Ti-6Al-4V & STS 321 & AgCuTi & Vacuum brazing & Yue, 2008 \\
\hline Pure Ti & Low carbon steel & $\begin{array}{c}\text { Ag-27.25Cu-12.5In-1.25Ti } \\
(\text { Incusil ABA) }\end{array}$ & Vacuum brazing & Elrefaey, 2009 \\
\hline Ti-6Al-4V & STS 304 & $\begin{array}{c}\text { Ti based (40Ti-20Zr-20Cu-20Ni), silver } \\
\text { based(Ag-5Pd), and nickel based } \\
\text { (Ni-7Cr-3.1B-4.5Si-3Fe-0.06C, BNi2 and } \\
\text { Ni-14Cr-10P-0.06C, BNi7) }\end{array}$ & Brazing & Chung, 2012 \\
\hline Ti-6Al-4V & STS 316L & AgCuZn & Vacuum Brazing & Tashi, 2014 \\
\hline TiAl alloy & 40Cr steel & CuTiNiZrV foil & Vacuum Brazing & Dong, 2015 \\
\hline Ti-6Al-4V & STS 316L & CuSi3 wire & Arc Brazing & Pardal, 2016 \\
\hline
\end{tabular}

적이 감소하는 것이 관찰되었다.

Yue et al. ${ }^{23)}$ 은 Ti-6Al-4V 합금과 STS 321 소재 에 $\mathrm{AgCuTi}$ 합금을 삽입재로 넣고, $920-980{ }^{\circ} \mathrm{C}$ 에서 접합하였다. $920{ }^{\circ} \mathrm{C}$ 에서 접합된 시편은 $\mathrm{CuTi}, \mathrm{Ag}$ 계, $\mathrm{Cu}_{4} \mathrm{Ti}$ 및 $\beta-\mathrm{Ti}$ 상으로 구성되며 전단강도는 최대 188 $\mathrm{MPa}$ 으로 $\mathrm{Ag}$ 계 상에서 연성파단이 발생했다. 온도가 $980{ }^{\circ} \mathrm{C}$ 로 증가함에 따라 접합부는 $\mathrm{Ag}$ 계, $\mathrm{CuTi}_{2}, \mathrm{Ti}^{-}$ $\mathrm{Cu}$ 계 및 $\beta-\mathrm{Ti}$ 상으로 구성되며 취성의 $\mathrm{Cu}-\mathrm{Ti} \mathrm{IMC}$ 형성으로 인해 전단강도가 감소하는 것을 확인할 수 있 었다.

Elrefaey et al. ${ }^{24)}$ 은 순 Ti 합금과 저탄소강 소재 접 합을 하기 위해 $200 \mu \mathrm{m}$ 의 Incusil $\mathrm{ABA}\left(\mathrm{Ag}-27.25 \mathrm{Cu}^{-}\right.$ $12.5 \mathrm{In}-1.25 \mathrm{Ti} \mathrm{wt} \%)$ 삽입재를 사용했다. $650-850$ ${ }^{\circ} \mathrm{C}$ 에서 15 분동안 접합한 결과 $750{ }^{\circ} \mathrm{C}$ 에서 접합부에 해로운 영향을 미치는 $\mathrm{IMC}$ 가 형성되지 않아 전단강도 는 최대 $113 \mathrm{MPa}$ 을 나타내었다. $650{ }^{\circ} \mathrm{C}$ 에서는 접합 부에 해로운 영향을 미치는 IMC는 관찰되지 않았으나 낮은 접합 온도로 인해 삽입재 용융이 부족했으며, 일 부 기공이 관찰되었다. $750{ }^{\circ} \mathrm{C}$ 이상의 조건에서는 steel 과 $\mathrm{Ti}$ 계면에 취성의 $\mathrm{TiCu}$ 상이 형성되어 접합부의 강도가 감소하였다.

Chung et al. ${ }^{25)}$ 은 Ti-6Al-4V 합금과 STS 304 소재를 브레이징하기 위해서 $\mathrm{Ti}$ 기반, $\mathrm{Ag}$ 기반, $\mathrm{Ni}$ 기 반한 4가지 종류의 필러를 880-1050 ${ }^{\circ} \mathrm{C}$ 에서 평가하여, $\mathrm{Ni}$ 기반의 $\mathrm{BNi}_{2}(\mathrm{Ni}-7 \mathrm{Cr}-3.1 \mathrm{~B}-4.5 \mathrm{Si}-3 \mathrm{Fe}-0.06 \mathrm{C})$ 와 $\mathrm{BNi}_{7}(\mathrm{Ni}-14 \mathrm{Cr}-10 \mathrm{P}-0.06 \mathrm{C})$ 이 가장 최적의 성능을 보여주었다고 보고하였다.

Tashi et al. ${ }^{26)}$ 은 Ti-6Al-4V 합금과 STS 316L 소 재에 $\mathrm{AgCuZn}$ 필러를 사용하여 진공브레이징을 수행 하고, 접합계면에서 $\mathrm{CuTi}, \mathrm{Fe}-\mathrm{Cu}-\mathrm{Ti}, \mathrm{Cu}_{3} \mathrm{Ti}_{1} \mathrm{Cu}_{3} \mathrm{Ti}_{2}$,
$\mathrm{TiAg}, \mathrm{Ag}_{3} \mathrm{Fe}_{2}$ 를 관찰하였다. 브레이징 시간과 온도가 증가할수록 증가하는 $\mathrm{Cu}-\mathrm{Ti}, \mathrm{Fe}-\mathrm{Cu}-\mathrm{Ti} \mathrm{IMC}$ 는 접합 성능을 저하시키지만 $\mathrm{TiAg} \mathrm{IMC}$ 는 접합부에 연성을 증가시키는 역할을 하였다.

Dong et al. ${ }^{27)}$ 은 $\mathrm{Ti}-\mathrm{Al}$ 합금을 $40 \mathrm{Cr}$ 강과의 이종 재료에 $\mathrm{CuTiNiZrV}$ 포일을 중간 삽입재로 넣어 브레 이징을 수행하였다. 적용된 포일 중 $\mathrm{Cu}_{43.75} \mathrm{Ti}_{37.5} \mathrm{Ni}_{6.25}$ $\mathrm{Zr}_{6.25} \mathrm{~V}_{6.25}$ (at.\%) 포일은 퍼짐성이 좋아 얇고 평평한 용접부 형성이 가능하였으나 $\mathrm{Ti}_{19} \mathrm{Al}_{6}$ 와 $\mathrm{Ti}_{2} \mathrm{Cu} \mathrm{IMC}$ 가 형성되어 접합부 강도가 저하되었고, $\mathrm{Cu}_{37.5} \mathrm{Ti}_{25} \mathrm{Ni}_{12.5^{-}}$ $\mathrm{Zr}_{12.5} \mathrm{~V}_{12.5}$ 포일은 강도 평가에서 $\mathrm{TiAl}$ 모재에서 파단 이 발생하면서 $107 \mathrm{MPa}$ 수준의 양호한 강도 확보가 가능하였다.

Pardal et al. ${ }^{28)}$ 은 Ti-6Al-4V 합금과 STS 316L 소재에 $\mathrm{CuSi}_{3}$ 와이어를 이용하여 아크 브레이징을 수 행하였다. 아크 용접공정으로는 저입열 구현이 가능한 CMT (Cold Metal Transfer) 공법을 사용하였고, $1.7 \mathrm{~mm}$ 갭을 조성하고 맞대기 조인트로 아크 브레이 징을 수행하였다. $\mathrm{Cu}$ 와 모재 사이에 $\mathrm{IMC}$ 형성은 피할 수 없었으나 $\mathrm{Fe}-\mathrm{Ti} \mathrm{IMC}$ 보다는 연성 확보에 유리한 $\mathrm{IMC}$ 가 형성되었다. 적용한 조건 범위에서는 입열이 높을 경우 젖음이 잘 발생하여 접합강도가 높은 결과가 관찰되었다.

\section{4. 용융용접}

용융용접을 이용하여 $\mathrm{Ti}$ 합금과 철계 소재를 용접할 경우 취성이 강한 $\mathrm{Fe}-\mathrm{Ti} \mathrm{IMC}$ 의 형성을 억제하는 것 이 불가능하다. 그래서 저입열 구현이 가능하고, 공정 제어가 쉬운 레이저 용접이나 전자빔용접을 적용한 연 
Table 4 Summary of fusion welding research for Ti/Steel dissimilar metal joining

\begin{tabular}{|c|c|c|c|c|c|}
\hline $\mathrm{Ti}$ & Steel & Interlayer & Process & Joint & $\begin{array}{c}\text { Author, } \\
\text { publication year }\end{array}$ \\
\hline Pure $\mathrm{Ti}$ & STS 304 & & Laser welding & Lap & Hiraga, $2002^{29)}$ \\
\hline Ti-6Al-4V & STS $316 \mathrm{~L}$ & $\begin{array}{l}\text { Pure } \mathrm{Cu} \\
(0.5 \mathrm{~mm})\end{array}$ & $\begin{array}{c}\text { Laser welding } \\
\text { Electron beam welding }\end{array}$ & Butt & Tomashchuk, 2011 \\
\hline Ti-6Al-4V & $42 \mathrm{CrMo}$ & & Laser welding & Lap & Zhao, 2011 \\
\hline Pure $\mathrm{Ti}$ & STS 316 & & Laser welding & Butt & Satoh, 2012 \\
\hline Pure $\mathrm{Ti}$ & STS 304 & $\mathrm{~V}, \mathrm{Ta}$ & Laser welding & BOP & Shanmugarajan, 2012 \\
\hline Ti-6Al-4V & STS 304L & $\begin{array}{l}\text { AZ31B } \\
\text { Mg wire }\end{array}$ & Laser welding & Butt & Gao, $2013^{46)}$ \\
\hline TiNi alloy & STS 304 & $\mathrm{Cu}$ foil & Laser welding & Butt & $\mathrm{Li}, 2013^{37)}$ \\
\hline Ti-6Al-4V & STS 304 & $\mathrm{Cu}$ foil & Laser welding & Butt & Mitelea, 2013 $3^{38)}$ \\
\hline Ti-6Al-4V & STS 316L & & Laser welding & $\mathrm{V}$ butt & Mohid, 2013 \\
\hline$a-\beta$ Ti alloy & STS 316L & $\mathrm{Cu}$ foil & Electron beam welding & Butt & Tomashchuk, 2013 ${ }^{39)}$ \\
\hline Ti-6Al-4V & STS 201 & & Laser welding & Butt & Chen, 2014 \\
\hline Pure $\mathrm{Ti}$ & $12 \mathrm{Kh} 18 \mathrm{~N} 10 \mathrm{~T}$ & $\mathrm{Ta}-\mathrm{Cu}$ & Laser welding & $\mathrm{V}$ butt & Cherepanov, $2014^{40)}$ \\
\hline Ti-6Al-4V & STS 304 & $\mathrm{Cu} 3 \mathrm{Si}$ wire & Laser-arc hybrid welding & $\mathrm{V}$ butt & Gao, 2015 $5^{41)}$ \\
\hline Ti-6Al-4V & STS $316 \mathrm{~L}$ & Pure $\mathrm{V}$ foil & Laser welding & Butt & Tomashchuk, 2015 ${ }^{45)}$ \\
\hline Pure $\mathrm{Ti}$ & STS 304 & & Laser welding & Lap & Chen, 2016 34$)$ \\
\hline Pure Ti & $12 \mathrm{Kh} 18 \mathrm{~N} 10 \mathrm{~T}$ & $\begin{array}{l}\text { Cu plate } \\
\text { (C11000) }\end{array}$ & Laser welding & Butt & Pugacheva, 2016 $6^{42)}$ \\
\hline Pure Ti & STS 304 & $\begin{array}{l}\text { ERCuSn-A, } \\
\text { ERNiCu-7 }\end{array}$ & Gas tungsten arc welding & $\mathrm{V}$ butt & Thonondaeng, 2016 $6^{43)}$ \\
\hline Ti-6Al-4V & STS 301L & $\mathrm{Nb}$ sheet & Laser welding & Butt & Zhang, 2016 $6^{47)}$ \\
\hline Ti-6Al-4V & STS 301L & & Laser welding & Butt & Zhang, 2019 35 ) \\
\hline
\end{tabular}

구가 많이 수행되었으며, 일부 연구에서는 가스 텅스텐 아크 용접과 중간 삽입재를 같이 이용하였다 (Table 4).

제살용접을 이용한 레이저 용접의 경우(Fig. $4 \mathrm{a})^{29-35)}$ 에는 $\mathrm{Ti}-\mathrm{Fe}, \mathrm{Ti}-\mathrm{Cr}$ 등의 $\mathrm{IMC}$ 형성에 대해 공통적으 로 보고되었으며, 합금 성분이 다양할수록 복잡한 중간 상이 관찰된다. 레이저 조사 위치 등 공정변수에 따른 $\mathrm{IMC}$ 의 거동과 접합강도의 변화에 대해 주로 연구되었다.

취성이 강한 IMC상을 제어하기 위하여 용융용접에 서 $\mathrm{Cu}^{36-43)}, \mathrm{V}^{44,45)}, \mathrm{Ta}^{40,44)}, \mathrm{Mg}^{46)}, \mathrm{Nb}^{47)}$ 등을 중간 삽입재가 사용되었다. $\mathrm{Cu}$ 와 $\mathrm{Mg}$ 등은 레이저 브레이징

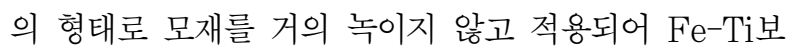
다 취성을 작은 $\mathrm{IMC}$ 형태로 접합부 조직을 구성할 수 있다. $\mathrm{V}, \mathrm{Ta}, \mathrm{Nb}$ 등은 모재에 합금이 용이한 소재들 로 용접부 강도를 향상시키기 위하여 사용되어 $\mathrm{V}$ 과 $\mathrm{Nb}$ 의 경우 $44,45,47)$ 의 경우 약 $370 \mathrm{MPa}$ 수준의 높은 접합강도가 확인되었으나 $\mathrm{Ta}$ 의 경우 산화 문제로 강도 확보에 실패하였다 ${ }^{44)}$. 레이저 용접을 적용한 $\mathrm{Ti}$ 합금/ 철계 소재의 이종재 용접에 대해서는 Auwal et al. ${ }^{48)}$ 에 의해 자세히 리뷰되었다.

아크 용접 ${ }^{43)}$ 과 레이저-아크 하이브리드 용접 ${ }^{41)}$ 의 경 우 용접으로 표기되었으나 실제적 접합형태는 윗절의
아크 브레이징 형태로 저융점의 $\mathrm{Cu}$ 계 와이어를 브레 이징 필러로 이용하고 열원으로 가스 텅스텐 아크(Fig. 4b)나 레이저-아크 복합열원을 사용한 형태로 적용되 었다.

\section{5. 기타 고상용접}

$\mathrm{Ti}$ 합금과 $\mathrm{Fe}$ 계 소재의 용접에는 확산접합 외 폭발 용접과 마찰용접 등의 고상용접공정에 대한 연구가 진 행되었다 (Table 5). 이들 고상용접의 경우 입열 및 공정온도가 낮아 $\mathrm{IMC}$ 층의 제어가 유리하지만 특수한 용접장비가 필요하거나 조인트 형상에 제한을 가지고 있다.

\section{1 폭발용접}

Kahramna et al. ${ }^{49)}$ 은 Fig. 5(a)에서 관찰할 수 있듯이 앤빌 위에 STS 304판재를 위치하고 5도의 경 사각을 두고 설치한 $\mathrm{Ti}-6 \mathrm{Al}-4 \mathrm{~V}$ 판재 위에 폭발을 발 생시켰으며 소재의 두께는 각각 $1.5 \mathrm{~mm}$ 였다. 짧은 공 정시간으로 인해 $\mathrm{IMC}$ 층은 계면에 형성되지 않았으며, 인장-전단 시험에서 모재 파단이 발생하였고, 180 도 
Table 5 Summary of solid state joining research for Ti/Steel dissimilar metal joining

\begin{tabular}{|c|c|c|c|c|c|}
\hline Ti & Steel & Interlayer & Process & Joint & $\begin{array}{c}\text { Author, } \\
\text { publication year }\end{array}$ \\
\hline Ti-6Al-4V & STS 304 & & Explosive welding & Lap & Kahraman, 2005 \\
\hline Pure Ti & STS 304L & & Friction welding & Butt & Dey, 2009 \\
\hline Pure Ti & STS 304 & & Friction stir welding & Double butt lap & Fazel-Najafabadi, 2010 \\
\hline Pure Ti & STS 304 & & Friction stir welding & Double butt lap & Fazel-Najafabadi, 2010 \\
\hline Ti-6Al-4V & STS 304 & & Friction stir welding & Lap & Campo, 2014 \\
\hline Ti-6Al-4V & 1018 steel & $\mathrm{Cu}, \mathrm{Nb}$ & $\begin{array}{c}\text { Vaporizing foil actuator } \\
\text { welding (VFAW) }\end{array}$ & Lap & Liu, 2015 \\
\hline
\end{tabular}

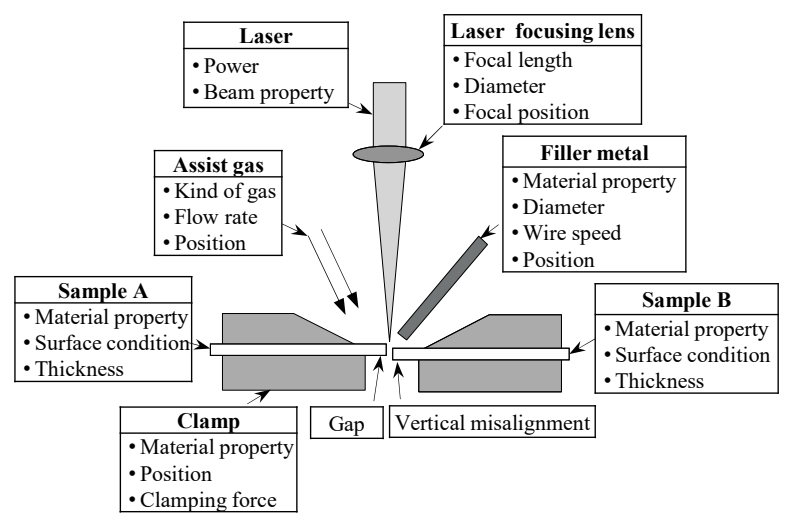

(a)

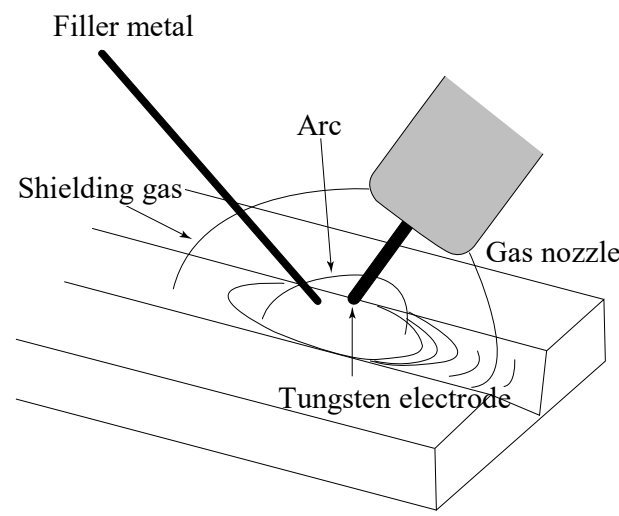

(b)

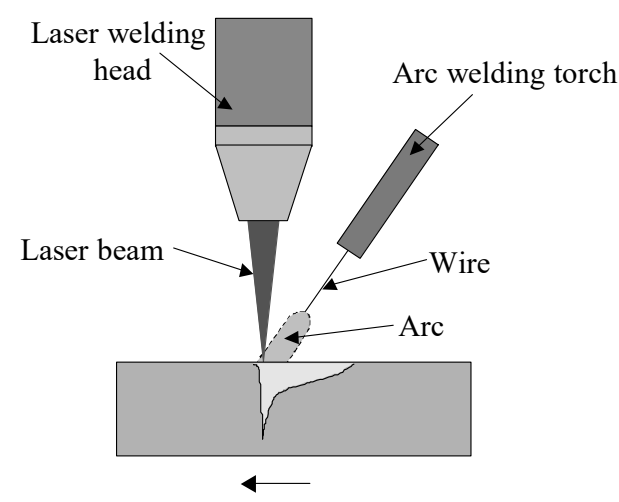

(c)

Fig. 4 Schematic of (a) laser keyhole welding, (b) gas tungsten arc welding, and (c) laser-arc hybrid processes $^{8)}$
굽힘시험을 통과하는 양호한 접합부를 형성하였다.

Liu et al. ${ }^{50)}$ 은 VFAW(Vaporizing foil actuator welding)을 이용하여 $0.41 \mathrm{~mm}$ 두께의 $\mathrm{Ti}-6 \mathrm{Al}-4 \mathrm{~V}$ 판재위에 중간층인 $\mathrm{Nb}(0.25 \mathrm{~mm})$ 과 $\mathrm{Cu}(0.13 \mathrm{~mm})$ 판재를 위치하고 가장 상층에 연강을 배치하여 순간적 기화압력을 이용하여 용접을 수행하였다. 순간적인 접 합에 의해서 $\mathrm{IMC}$ 는 형성되지 않고 양호한 용접부를 형성하였으며, $910{ }^{\circ} \mathrm{C}$ 에서 24 시간 동안 열처리를 수 행한 경우에도 계면에 $\mathrm{IMC}$ 가 성장하지 않는 화학적으 로 안정된 용접이 가능하여, 고온 동작이 필요한 부품 에서도 안정성 확보가 가능함을 확인하였다.

\section{2 마찰용접과 마찰교반용접}

Dey et al. ${ }^{51)}$ 은 원자력 발전부품에 요구되는 이종재 접합부를 제작하기 위하여 봉형의 순 $\mathrm{Ti}$ 금속과 STS $304 \mathrm{~L}$ 소재에 대한 마찰용접을 시도하였다. 적절한 마 찰용접공정변수 선정을 통하여 인장시험에서 $\mathrm{Ti}$ 금속 모재가 파단되는 접합부를 형성하였다. 접합공정에서 상대적으로 변형이 쉬운 $\mathrm{Ti}$ 금속에서 플래쉬가 발생하 였으며, STS 모재와의 경계가 유지되면서 동적 재결정 이 $\mathrm{Ti}$ 쪽으로 진행되었다. IMC 층은 STS 모재와 접

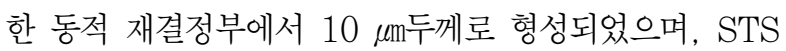
소재에서 $\mathrm{Fe}, \mathrm{Cr}$ 이 $\mathrm{a}-\mathrm{Ti}$ 로의 확산되었다.

Fazl-Najafabadi et al. ${ }^{52,53)}$ 은 순 Ti 금속과 STS 304 합금과의 마찰교반용접(Fig. 5b)을 수행하였다. 상하판 배열을 바꾸면서 연구를 진행하였고, $4 \mathrm{~mm}$ 두 께의 소재의 계면을 가공하여 겹침-맞대기 조인트를 만 들어서 공구강 숄더와 $\mathrm{WC}$ 핀을 이용하여 용접을 수행 하였다. 두 소재 배열 모두에서 $\mathrm{TiFe}_{2}$ 가 아닌 $\mathrm{TiFe}$ $\mathrm{IMC}$ 층이 $3 \mu \mathrm{m}$ 정도의 두께로 형성된다고 보고하였으 며, Ti이 상판일 경우 보다 STS가 상판일 경우 강도가 $30 \%$ 증가하면서 $\mathrm{Ti}$ 과 유사한 강도 확보가 가능하였다.

Campo et al. ${ }^{54)}$ 은 $1.6 \mathrm{~mm}$ 두께의 Ti-6Al-4V 합 금을 상판에 위치하고 $2.5 \mathrm{~mm}$ 두께의 1018 강재를 하판에 겹치기 조인트로 배치하고 마찰교반용접을 수행 


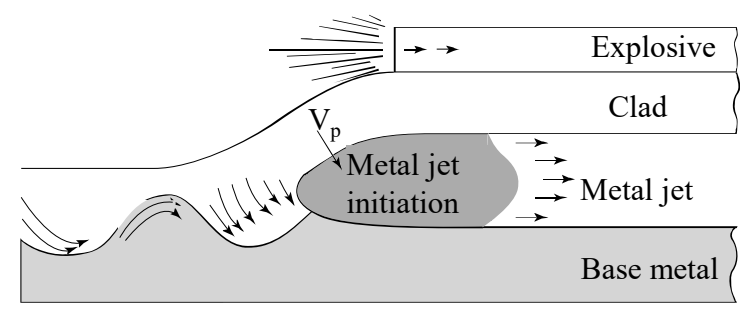

(a)

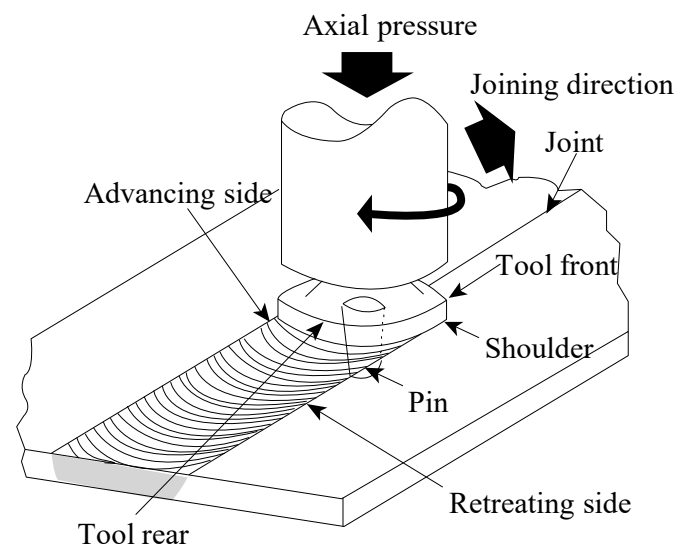

(b)

Fig. 5 Schematic of (a) explosion welding and (b) friction stir welding process ${ }^{8)}$

하였다. $\mathrm{Ti}$ 합금이 동작온도에서 강도가 더 높아 상판 에 위치하는 것이 유리하였으며, 용접 후 상온에서 안 정된 $\beta-\mathrm{Ti}$ 이 형성되었다. $\mathrm{Ti}$ 원소가 $\mathrm{STS}$ 소재 쪽으로 확산하면서 $5 \mu \mathrm{m}$ 정도의 $\mathrm{TiFe}_{2} \mathrm{IMC}$ 층이 관찰되었으 며, 용접공정에 의한 연화가 열영향부에서 관찰되었다.

\section{6. 직접 접합부 $\mathrm{IMC}$ 의 형성}

\section{1 확산접합부}

Ghosh et al.의 연구 ${ }^{10)}$ 에서는 중간 삽입재 없이 순 수 $\mathrm{Ti}$ 금속과 STS 304 소재의 확산접합이 시도되었 다. $950{ }^{\circ} \mathrm{C}$ 에서 2 시간 확산접합할 경우 계면에서 STS 쪽으로 $\mathrm{Ti}$ 가 확산되어 $20 \mu \mathrm{m}$ 정도의 $\sigma$ 상 $(\mathrm{Fe} \sim 59.8-61.8$ at.\%, $\mathrm{Cr} \sim 29.2-31.8$ at.\%, $\mathrm{Ni} \sim 4.7-5.8$ at.\% and $\mathrm{Ti})$ 을 형성하고, 이 층에 접해서 $\mathrm{Fe}_{2} \mathrm{Ti}(\mathrm{Cr}, \mathrm{Ni}) \mathrm{IMC}$ 층 (Fig. 1의 1), 1-2 $\mu \mathrm{m}$ 두께의 얇은 $\mathrm{TiCr}_{2}+\mathrm{Fe}_{2} \mathrm{Ti}(\mathrm{Cr}$ ) 층 (Fig. 6의 2번 영역)과 $\mathrm{FeTi}(\mathrm{Cr}, \mathrm{Ni}) \mathrm{IMC}$ 층 (Fig. 6의 3번 영역)이 형성된다. 이 때 $\mathrm{Fe}_{2} \mathrm{Ti} \mathrm{IMC}$

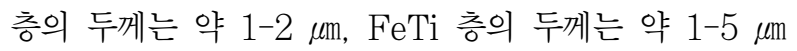
이다. Campo et $\mathrm{al}^{54)}$ 의 연구에서도 동일하게 $\mathrm{Ti}$ 이 STS 소재로 확산되면서 $5 \mu \mathrm{m}$ 두께의 IMC 층이 확인 되었다.

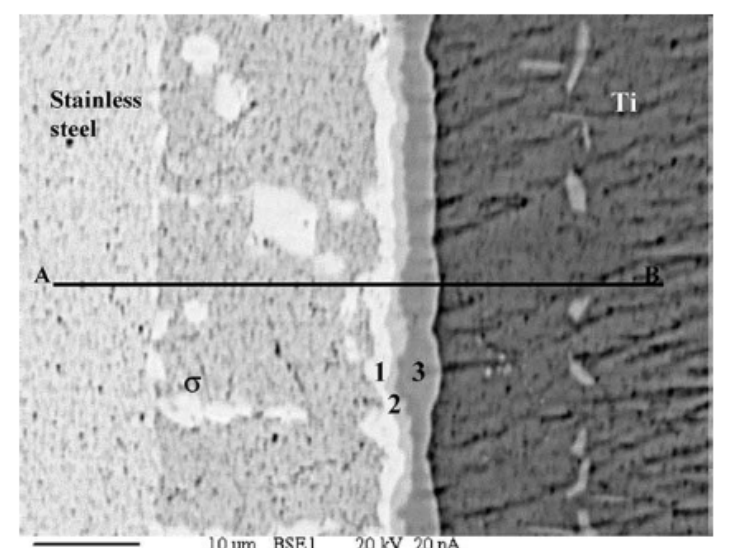

Fig. 6 Diffusion welded joint of Ti-6Al-4V alloy and STS 304 steel $^{10)}$
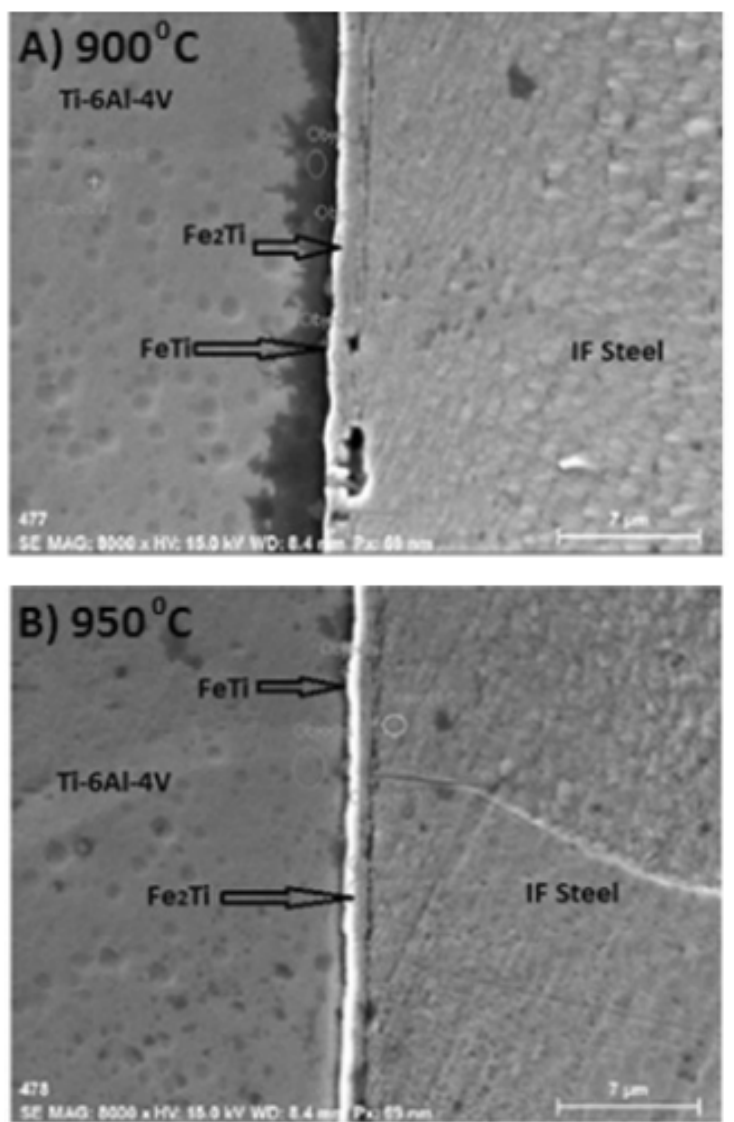

Fig. 7 Diffusion welded joint of Ti-6Al-4V alloy and IF steel $^{14)}$

Kaya et al. ${ }^{14)}$ 의 연구에 따르면 $\mathrm{Ti}-6 \mathrm{Al}-4 \mathrm{~V}$ 합금과 $\mathrm{IF}$ (Interstitial free) 강재의 확산접합부에서는 위의 $\mathrm{Ti}$ 합금/STS 접합부에 비해 간단한 IMC 층이 관찰되 었다. $\mathrm{IF}$ 강에서 $\mathrm{Fe}$ 원소가 $\mathrm{Ti}$ 합금 쪽으로 확산이 되 면서 $\mathrm{Ti}-6 \mathrm{Al}-4 \mathrm{~V}$ 합금 쪽에는 $\mathrm{FeTi} \mathrm{IMC}$ 층이 형성되 었으며, IF 강재 쪽으로는 $\mathrm{Fe}_{2} \mathrm{Ti} \mathrm{IMC}$ 층이 형성되었 다 (Fig. 7). 상대적으로 높은 $950{ }^{\circ} \mathrm{C}$ 의 공정시간에서 
도 $\mathrm{IMC}$ 층의 총 두께는 $1.5 \mu \mathrm{m}$ 이내로 형성되어 접합 강도 확보에 큰 문제가 없었다.

\section{2 마찰용접과 마찰교반용접}

Fazel-Najafabadi et al. ${ }^{52,53)}$ 은 순 $\mathrm{Ti}$ 금속과 STS 304 소재에 대해 상하판 소재조합을 변경하면서 겹치 기 $\mathrm{FSW}$ 를 수행하였는데, $\mathrm{Ti}$ 가 STS 쪽으로 확산되어 서 $\mathrm{TiFe}_{2}$ 가 아닌 $\mathrm{TiFe} \mathrm{IMC}$ 가 $4 \mu \mathrm{m}$ 이내로 형성된다 고 보고하였으며, 이를 $\mathrm{TiFe}$ 가 $\mathrm{TiFe}_{2}$ 에 비해 자유에너 지가 더 낮기 때문이라고 설명하였다.

Dey et al. ${ }^{51)}$ 은 순 Ti 금속과 STS 304 소재를 봉 형으로 마찰용접을 수행하였는데, 변형이 발생하는 $\mathrm{Ti}$ 쪽에서 $\mathrm{IMC}$ 층과 동적 재결정이 발생하였다. Fig. 8 을 통해 $\mathrm{STS}$ 소재로부터 $\mathrm{Fe}$ 와 $\mathrm{Cr}$ 이 용접층으로 확산 되면서 $10 \mu \mathrm{m}$ 정도의 두께를 가지고 주된 성분은 $\mathrm{Ti}$, $\mathrm{Fe}$, 그리고 $\mathrm{Cr}$ 으로 확인되었다.

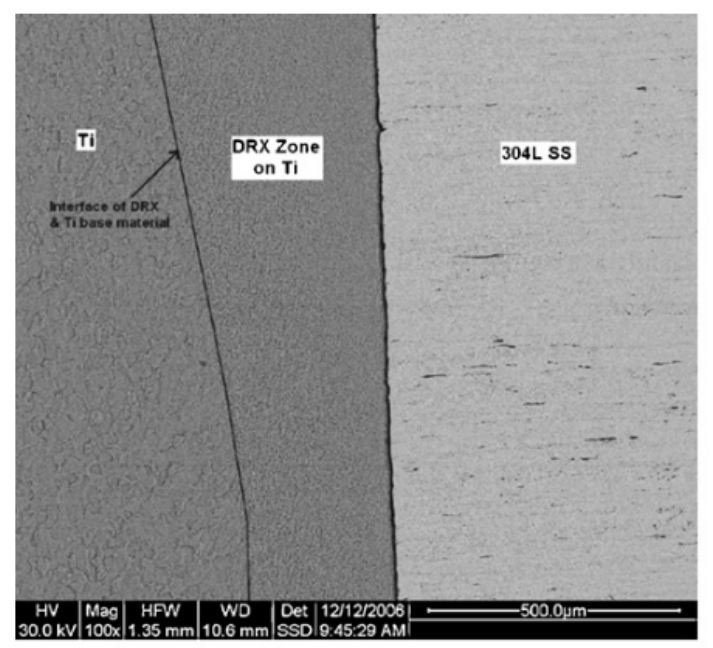

(a)

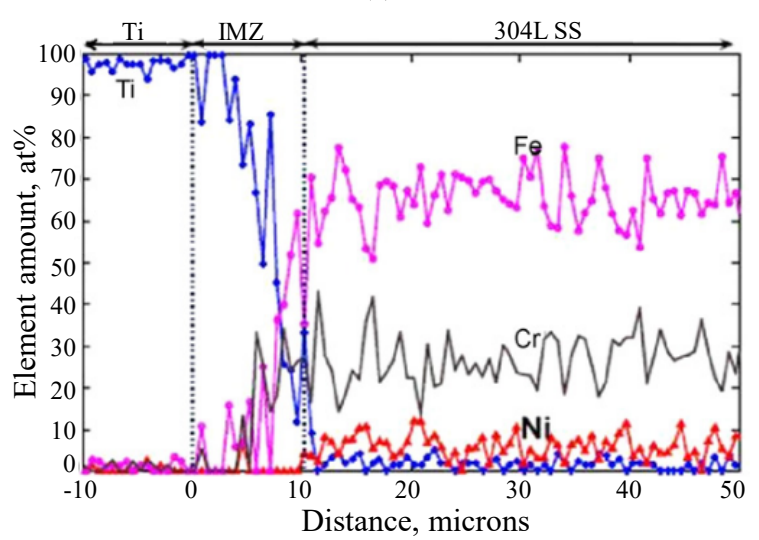

(b)

Fig. 8 (a) SEM-BSE micrograph of Ti/STS 304L interface, and (b) corresponding SEM-EDS line scan across the interface ${ }^{51)}$

\section{3 레이저용접}

Zhang et al. ${ }^{35)}$ 은 Ti-6Al-4V 합금과 STS $301 \mathrm{~L}$ 소재의 맞대기 조인트에 레이저 용융을 이용한 접합기 술을 제안하였다. 이 공정에서 레이저는 $\mathrm{Ti}$ 합금에만 조 사되고 이 때 두 소재의 계면에 공정조성의 액상(eutectic liquid)이 형성되면서 $\mathrm{Ti}$ 합금과 STS 소재간의 접합 이 이루어진다. 기존 확산접합 연구와 유사하게 $\mathrm{Ti}$ 원 소가 STS 쪽으로 확산되면서 $\mathrm{Ti}$ 합금과 가까운 쪽은 $\mathrm{TiFe} \mathrm{IMC}$ 층이, STS 소재와 가까운 쪽은 $\mathrm{TiFe}_{2}$ $\mathrm{IMC}$ 층이 형성되는데 $\mathrm{Ti}$ 모재와 $\mathrm{TiFe} \mathrm{IMC}$ 층 사이 에 $\beta-\mathrm{Ti}$ 층이 형성되었다.

Chen et al. ${ }^{33)}$ 은 Ti-6Al-4V 합금과 STS 201 소 재의 맞대기 레이저 용접을 수행하였다. 레이저빔을 STS 소재 쪽에 조사할 경우 용접성이 더 우수하였으 며, $\mathrm{Ti}$ 합금에 가까운 층(Layer I)은 $\mathrm{FeTi}+\mathrm{a}-\mathrm{Ti}$ 로 구성되고, $\mathrm{STS}$ 에 가까운 층은 $\mathrm{FeTi}$ (짙은 회색, $\mathrm{C}$ ), $\mathrm{Fe}_{2} \mathrm{Ti}$ (회색, $\mathrm{D}$ 와 $\mathrm{E}$ )과 $\tau$ 상 $\left(\mathrm{Ti}_{5} \mathrm{Fe}_{17} \mathrm{Cr}_{5}\right.$, 밝은 색, $\left.\mathrm{F}\right)$ 으로 구성되었다고 보고하였다 (Fig. 9).

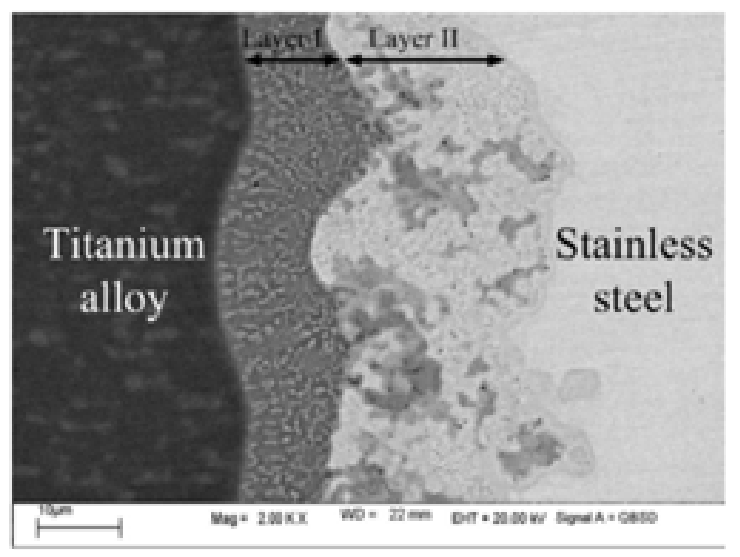

(a)

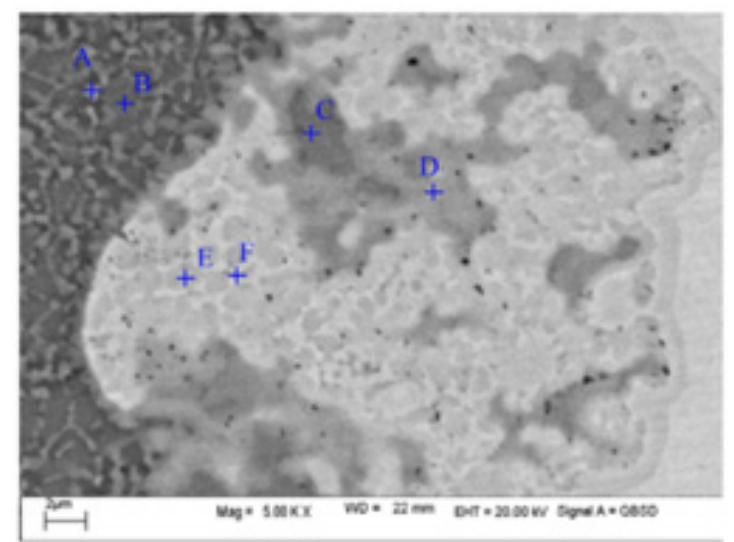

(b)

Fig. 9 Microstructures of Ti/STS laser welded joint. (a) interfacial microstructures and (b) magnification of layer II in the Fig. 9(a) ${ }^{33)}$ 


\section{7. 결 론}

$\mathrm{Ti}$ 합금은 우수한 기계/재료적 특성에도 불구하고 소 재 및 가공, 조립 비용이 상대적으로 높아 활용이 제한 적이었다. $\mathrm{Ti}$ 합금과 $\mathrm{Fe}$ 계 소재의 용접 접합에서의 품질과 생산성을 확보할 경우 기능성과 경제성을 동시 에 만족할 수 있는 솔루션 개발이 가능하다. 기존의 확 산접합과 브레이징의 경우 적용 부품의 형상이나 생산 성이 제한적이므로 용융용접이나 접근이 용이한 고상용 접방법의 개발이 요구된다. $\mathrm{FeTi}, \mathrm{Fe}_{2} \mathrm{Ti}$ 와 같은 $\mathrm{IMC}$ 층 형성을 충분히 제어하면서 생산성 확보가 가능한 고 에너지 용접이나 저입열 용융용접, 마찰교반용접 등에 기반한 새로운 용접 공정들이 제안될 것으로 예상된다.

ORCID: Hyeonjeong You: https://orcid.org/0000-0002-0734-1743 ORCID: Taehyun Lee: http://orcid.org/0000-0003-0010-972X ORCID: Minjung Kang: http://orcid.org/0000-0003-1894-4301 ORCID: Cheolhee Kim: http://orcid.org/0000-0003-4127-3171

\section{References}

1. Korean Welding and Joining Society, Welding and Joining Handbook, 1: Ferrous and Non-Ferrous Materials, Korean Welding and Joining Society, Daejeon, Korea (2008).

2. Y. N. Ahn and C. H. Kim, Yb:YAG Laser and Electron Beam Welding of Ti-6Al-4V Alloy, J. Korean Weld. Join. Soc. 29(6) (2011) 4-8.

https://doi.org/10.5781/kwjs.2011.29.6.624

3. J. L. Murray, Phase Diagrams of Binary Titanium Alloys, ASM Int. (1987).

4. G. Cacciamani, J. De Keyzer, R. Ferro, U. E. Klotz, J. Lacaze, and P. Wollants, Critical evaluation of the $\mathrm{Fe}-\mathrm{Ni}, \mathrm{Fe}-\mathrm{Ti}$ and $\mathrm{Fe}-\mathrm{Ni}-\mathrm{Ti}$ alloy systems, Intermetallics, 14 (2006) 1312-1325.

https://doi.org/10.1016/j.intermet.2005.11.028

5. http://www.matweb.com

6. Z. Yu, Review of Ti to Steel Dissimilar Joining, Res. Develop. Mater. Sci. 5(5) (2018). https://doi.org/10.31031/rdms.2018.05.000623

7. Y. Gao, T. Tsumura, and K. Nakata, Dissimilar Welding of Titanium Alloys to Steels, Trans. JWRI, 41(2) (2012) 7-12.

8. Korean Welding and Joining Society, Welding and Joining Handbook, 3: Process and Thermal Processing, Korean Welding and Joining Society, Daejeon, Korea (2008).

9. M. Ghosh and S. Chatterjee, Characterization of Transition Joints of Commercially Pure Titanium to 304 Stainless Steel, Mater. Charact. 48(5) (2002) 393-399.

10. M. Ghosh, K. Bhanumurthy, G. B. Kale, J. Krishnan and S. Chatterjee, Diffusion Bonding of Titanium to 304 Stainless Steel, J. Nucl. Mater. 322(2-3) (2003) 235-241. https://doi.org/10.1016/j.jnucmat.2003.07.004

11. M. Ghosh and S. Chatterjee, Diffusion Bonded Transition Joints of Titanium to Stainless Steel with Improved
Properties, Mater. Sci. Eng. A 358(1-2) (2003) 152-158. https://doi.org/10.1016/s0921-5093(03)00298-3

12. S. Kundu, M. Ghosh, and S. Chatterjee, Diffusion Bonding of Commercially Pure Titanium and 17-4 Precipitation Hardening Stainless Steel, Mater. Sci. Eng. A 428(1-2) (2006) 18-23.

https://doi.org/10.1016/j.msea.2005.10.047

13. S. Kundu and S. Chatterjee, Diffusion Bonding between Commercially Pure Titanium and Micro-Duplex Stainless Steel, Mater. Sci. Eng. A 480(1-2) (2008) 316-322. https://doi.org/10.1016/j.msea.2007.07.033

14. M. Kaya, M. Kılıc, I. Kırık, E. M. Karakurt, and B. Gulenc, Diffusion Bonding between Ti-6Al-4V Alloy and Interstitial Free Steel, Materialwiss. Werkstofftech. 48(7) (2017) 661-665. https://doi.org/10.1002/mawe.201700003

15. S. Kundu, M. Ghosh, A. Laik, K. Bhanumurthy, G. B. Kale, and S. Chatterjee, Diffusion Bonding of Commercially Pure Titanium to 304 Stainless Steel Using Copper Interlayer, Mater. Sci. Eng. A 407(1-2) (2005) 154-160. https://doi.org/10.1016/j.msea.2005.07.010

16. S. Kundu and S. Chatterjee, Characterization of Diffusion Bonded Joint between Titanium and 304 Stainless Steel Using a Ni Interlayer, Mater. Charact. 59(5) (2008) 631-637. https://doi.org/10.1016/j.matchar.2007.05.015

17. S. Kundu, B. Mishra, D. L. Olson, and S. Chatterjee, Interfacial Reactions and Strength Properties of Diffusion Bonded Joints of Ti64 Alloy and 17-4PH Stainless Steel Using Nickel Alloy Interlayer, Mater. Des. 51 (2013) 714-722. https://doi.org/10.1016/j.matdes.2013.04.088

18. P. He, X. Yue, and J. H. Zhang, Hot Pressing Diffusion Bonding of a Titanium Alloy to a Stainless Steel with an Aluminum Alloy Interlayer, Mater. Sci. Eng. A 486 (1-2) (2008) 171-176. https://doi.org/10.1016/j.msea.2007.08.076

19. A. Elrefaey and W. Tillmann, Solid State Diffusion Bonding of Titanium to Steel Using a Copper Base Alloy as Interlayer, J. Mater. Process. Technol. 209(5) (2009) 2746-2752.

https://doi.org/10.1016/j.jmatprotec.2008.06.014

20. P. Camargo, R. Trevisan, and S. Liu, Microstructural Characterization of Titanium to 304 Stainless Steel Brazed Joints, Weld. J. 72(12) (1993) 537.

21. C. Liu, C. Ou, and R. Shiue, The Microstructural Observation and Wettability Study of Brazing Ti-6al-4v and 304 Stainless Steel Using Three Braze Alloys, J. Mmater. Sci. 37(11) (2002) 2225-2235. https://doi.org/10.1023/A:1015356930476

22. E. Atasoy and N. Kahraman, Diffusion Bonding of Commercially Pure Titanium to Low Carbon Steel Using a Silver Interlayer, Mater. Charact. 59(10) (2008) 14811490.

https://doi.org/10.1016/j.matchar.2008.01.015

23. X. Yue, P. He, J. C. Feng, J. H. Zhang, and F. Q. Zhu, 
Microstructure and Interfacial Reactions of Vacuum Brazing Titanium Alloy to Stainless Steel Using an AgCuTi Filler Metal, Mater. Charact. 59(12) (2008) 1721-1727.

https://doi.org/10.1016/j.matchar.2008.03.014

24. A. Elrefaey and W. Tillmann, Effect of Brazing Parameters on Microstructure and Mechanical Properties of Titanium Joints, J. Mater. Process. Technol. 209(10) (2009) 4842-4849. https://doi.org/10.1016/j.jmatprotec.2009.01.006

25. T. Chung, J. Kim, J. Bang, B. Rhee, and D. Nam, Microstructures of Brazing Zone between Titanium Alloy and Stainless Steel Using Various Filler Metals, Trans. Nonferr. Met. Soc. China, 22 (2012) s639-s644. https://doi.org/10.1016/s1003-6326(12)61778-6

26. R. Soltani Tashi, S. a. A. Akbari Mousavi, and M. Mazar Atabaki, Diffusion Brazing of Ti-6Al-4V and Austenitic Stainless Steel Using Silver-Based Interlayer, Mater. Des. (1980-2015), 54 (2014) 161-167. https://doi.org/10.1016/j.matdes.2013.07.103

27. H. Dong, Z. Yang, Z. Wang, D. Deng, and C. Dong, Cutinizrv Amorphous Alloy Foils for Vacuum Brazing of TiAl Alloy to 40Cr Steel, J. Mater. Sci. Technol. 31(2) (2015) 217-222. https://doi.org/10.1016/j.jmst.2014.04.003

28. G. Pardal, S. Ganguly, S. Williams, and J. Vaja, Dissimilar Metal Joining of Stainless Steel and Titanium Using Copper as Transition Metal, Int. J. Adv. Manuf. Technol. 86(5-8) (2016) 1139-1150. https://doi.org/10.1007/s00170-015-8110-2

29. H. Hiraga, K. Fukatsu, K. Ogawa, M. Nakayama, and Y. Muto, Nd:YAG Laser Welding of Pure Titanium to Stainless Steel, Weld. Int. 16(8) (2002) 623-631.

30. S. Zhao, G. Yu, X. He, Y. Zhang, and W. Ning, Numerical Simulation and Experimental Investigation of Laser Overlap Welding of Ti6Al4V and 42CrMo, $J$. Mater. Process. Technol. 211(3) (2011) 530-537. https://doi.org/10.1016/j.jmatprotec.2010.11.007

31. G. Satoh, Y. L. Yao, and C. Qiu, Strength and Microstructure of Laser Fusion-Welded Ti-SS Dissimilar Material Pair, Int. J. Adv. Manuf. Technol. 66(1-4) (2012) 469-479. https://doi.org/10.1007/s00170-012-4342-6

32. Z. Mohid, M. A. Liman, M. R. A. Rahman, N. H. Rafai, and E. A. Rahim, Dissimilar Materials Laser Welding Characteristics of Stainless Steel and Titanium Alloy, Appl. Mech. Mater. 465-466 (2013) 1060-1064. https://doi.org/10.4028/www.scientific.net/AMM.465466.1060

33. S. Chen, M. Zhang, J. Huang, C. Cui, H. Zhang, and X. Zhao, Microstructures and Mechanical Property of Laser Butt Welding of Titanium Alloy to Stainless Steel, Mater. Des. 53 (2014) 504-511. https://doi.org/10.1016/j.matdes.2013.07.044

34. H. C. Chen, G. Bi, B. Y. Lee, and C. K. Cheng, Laser Welding of CP Ti to Stainless Steel with Different Temporal Pulse Shapes, J. Mater. Process. Technol. 231
(2016) 58-65.

https://doi.org/10.1016/j.jmatprotec.2015.12.016

35. Y. Zhang, J. Zhou, D. Sun, and X. Gu, Nd:Yag Laser Welding of Dissimilar Metals of Titanium Alloy to Stainless Steel without Filler Metal Based on a Hybrid Connection Mechanism, J. Mater. Res. Technol. 9(2) (2019) 1662-1672.

https://doi.org/10.1016/j.jmrt.2019.12.001

36. I. Tomashchuk, P. Sallamand, H. Andrzejewski, and D. Grevey, The Formation of Intermetallics in Dissimilar Ti6Al4V/Copper/AiSi 316 L Electron Beam and Nd: YAG Laser Joints, Intermetallics, 19(10) (2011) 14661473.

https://doi.org/10.1016/j.intermet.2011.05.016

37. H. Li, D. Sun, X. Gu, P. Dong, and Z. Lv, Effects of the Thickness of $\mathrm{Cu}$ Filler Metal on the Microstructure and Properties of Laser-Welded TiNi Alloy and Stainless Steel Joint, Mater. Des. 50 (2013) 342-350.

https://doi.org/10.1016/j.matdes.2013.03.014

38. I. Mitelea, C. Groza, and C. Craciunescu, Copper Interlayer Contribution on $\mathrm{Nd}$ :Yag Laser Welding of Dissimilar Ti-6al-4v Alloy with X5CrNi18-10 Steel, $J$. Mater. Eng. Perform. 22(8) (2013) 2219-2223. https://doi.org/10.1007/s11665-013-0507-1

39. I. Tomashchuk, P. Sallamand, N. Belyavina, and M. Pilloz, Evolution of Microstructures and Mechanical Properties During Dissimilar Electron Beam Welding of Titanium Alloy to Stainless Steel Via Copper Interlayer, Mater. Sci. Eng. A 585 (2013) 114-122. https://doi.org/10.1016/j.msea.2013.07.050

40. A. N. Cherepanov, A. M. Orishich, and V. I. Mali, Laser Welding of Stainless Steel with a Titanium Alloy with the Use of a Multilayer Insert Obtained in an Explosion, Combust. Explos. Shock Waves, 50(4) (2014) 483-487. https://doi.org/10.1134/s0010508214040182

41. M. Gao, C. Chen, L. Wang, Z. Wang, and X. Zeng, LaserArc Hybrid Welding of Dissimilar Titanium Alloy and Stainless Steel Using Copper Wire, Metall. Mater. Trans. A 46(5) (2015) 2007-2020.

https://doi.org/10.1007/s11661-015-2798-3

42. N. B. Pugacheva, M. V. Myasnikova, and N. S. Michurov, Simulation of the Elastic Deformation of Laser-Welded Joints of an Austenitic Corrosion-Resistant Steel and a Titanium Alloy with an Intermediate Copper Insert, Phy. Met. Metallogr. 117(2) (2016) 195-203. https://doi.org/10.1134/s0031918x15120078

43. T. Thonondaeng, K. Fakpan, and K. Eidhed, Dissimilar Metals Welding of CP Titanium to 304 Stainless Steel Using GTAW Process, Appl. Mech. Mater. 848 (2016) 43-47. https://doi.org/10.4028/www.scientific.net/AMM.848.43

44. B. Shanmugarajan and G. Padmanabham, Fusion Welding Studies Using Laser on Ti-SS Dissimilar Combination, Opt. Lasers Eng. 50(11) (2012) 1621-1627. https://doi.org/10.1016/j.optlaseng.2012.05.008 
45. I. Tomashchuk, D. Grevey, and P. Sallamand, Dissimilar Laser Welding of AISI 316L Stainless Steel to Ti6-A14-6v Alloy Via Pure Vanadium Interlayer, Mater. Sci. Eng. A 622 (2015) 37-45.

https://doi.org/10.1016/j.msea.2014.10.084

46. M. Gao, S. W. Mei, Z. M. Wang, X. Y. Li, and X. Y. Zeng, Characterisation of Laser Welded Dissimilar Ti/Steel Joint Using Mg Interlayer, Sci. Technol. Weld. Join. 17(4) (2013) 269-276. https://doi.org/10.1179/1362171812y.0000000002

47. Y. Zhang, D. Sun, X. Gu, and H. Li, A Hybrid Joint Based on Two Kinds of Bonding Mechanisms for Titanium Alloy and Stainless Steel by Pulsed Laser Welding, Mater. Lett. 185 (2016) 152-155. https://doi.org/10.1016/j.matlet.2016.08.138

48. S. T. Auwal, S. Ramesh, F. Yusof, and S. M. Manladan, A Review on Laser Beam Welding of Titanium Alloys, Int. J. Adv. Manuf. Technol. 97(1-4) (2018) 1071-1098. https://doi.org/10.1007/s00170-018-2030-x

49. N. Kahraman, B. G?len?, and F. Findik, Joining of Titanium/Stainless Steel by Explosive Welding and Effect on Interface, J. Mater. Process. Technol. 169(2) (2005) 127-133.

https://doi.org/10.1016/j.jmatprotec.2005.06.045
50. B. Liu, A. Vivek, W. Lin, C. Prothe, and G. Daehn, Solid-State Dissimilar Joining of Ti-Fe with $\mathrm{Nb}$ and Cu Interlayers, Weld. J. 94(7) (2015) 219s-224s.

51. H. C. Dey, M. Ashfaq, A. K. Bhaduri, and K. P. Rao, Joining of Titanium to 304L Stainless Steel by Friction Welding, J. Mater. Process. Technol. 209(18-19) (2009) 5862-5870. https://doi.org/10.1016/j.jmatprotec.2009.06.018

52. M. Fazel-Najafabadi, S. F. Kashani-Bozorg, and A. ZareiHanzaki, Joining of CP-Ti to 304 Stainless Steel Using Friction Stir Welding Technique, Mater. Des. 31(10) (2010) 4800-4807. https://doi.org/10.1016/j.matdes.2010.05.003

53. M. Fazel-Najafabadi, S. F. Kashani-Bozorg, and A. ZareiHanzaki, Dissimilar Lap Joining of 304 Stainless Steel to CP-Ti Employing Friction Stir Welding, Mater. Des. 32(4) (2011) 1824-1832.

https://doi.org/10.1016/j.matdes.2010.12.026

54. K. N. Campo, L. C. Campanelli, L. Bergmann, J. F. D. Santos, and C. Bolfarini, Microstructure and Interface Characterization of Dissimilar Friction Stir Welded Lap Joints between Ti-6Al-4V and AISI 304, Mater. Des. (1980-2015) 56 (2014) 139-145. https://doi.org/10.1016/j.matdes.2013.11.002 